\title{
É POSSÍVEL PENSAR DE OUTRO MODO A EDUCAÇÃO EM ENFERMAGEM?a
}

\author{
Is it Possible to View Nursing Education Differently? \\ ¿Es Posible Pensar de Otra Manera la Educación en Enfermería?
}

Maria Henriqueta Luce Kruse ${ }^{1}$

\section{Resumo}

Discorre sobre as práticas pedagógicas que constituem a enfermeira, onde se estabelecem, regulam e modificam as relações deste sujeito consigo mesmo e nas quais se constitui a experiência de si. Aponta os discursos que a produzem, as condições de possibilidades do aparecimento desta profissão no Brasil, os repertórios de modos de experiência de si e os dispositivos para formação de seus membros, destacando quatro aspectos da Tese "Os poderes dos corpos frios": a disciplina de Anatomia, as técnicas de enfermagem, o exame físico e os diagnósticos de enfermagem, aqui vistos como dispositivos produtores dos corpos frios. Aponta tais estratégias de ensino como representativas de um determinado modo de ensinar enfermagem, ressaltando que os mecanismos disciplinares que permeiam o modo como ensinamos podem nos impedir de pensar de outro modo o ensino de enfermagem.

Palavras-chave: Educação em Enfermagem. Educação Superior. História da Enfermagem.

\section{Abstract}

Considers the pedagogical practices that are used in nursing where the relations of this person are established, regulated, and modified with themselves and where their own experience is made up. It points out the discourses that produce this, the conditions of possibilities of the rise of this profession in Brazil, the repertoires of ways of experiencing themselves, and the instruments for the formation of its members, focusing on four aspects of the Thesis The powers of the cold bodies: the discipline of Anatomy, the nursing techniques, the physical exam, and the nursing diagnosis here viewed as apparatuses that produce cold bodies. It points out such teaching strategies as representative of a certain way of teaching nursing, pointing out that the disciplinary mechanisms that permeate the way how we teach can keep us from thinking that nursing instruction could be done differently.

Keywords:

Education, Nursing. Education, Higher. History of Nursing.

\section{Resumen}

Discurre sobre las prácticas pedagógicas que constituyen la enfermera, donde se establecen, regulan y modifican las relaciones de este sujeto consigo mismo y en las cuales se constituye la experiencia de sí. Apunta a los discursos que la producen, las condiciones de posibilidades del nacimiento de esta profesión en Brasil, los repertorios de modos de experiencia de sí y los dispositivos para la formación de sus miembros, destacando cuatro aspectos de la Tesis. "Los poderes de los cuerpos fríos: la disciplina de Anatomía", las técnicas de enfermería, el examen físico y los diagnósticos de enfermería, aquí vistos como dispositivos productores de los cuerpos fríos. Apunta tales estrategias de enseñanza como representativas de un determinado modo de enseñar enfermería, resaltando que los mecanismos disciplinarios que atraviesan la forma de cómo enseñamos nos pueden impedir pensar de otra manera la enseñanza de enfermería.

Palabras clave: Educación en Enfermería. Educación Superior. Historia de la Enfermería. 


\section{PARA PENSAR DE OUTRO MODO}

Neste texto proponho "pensar de outro modo" sobre coisas que são muitas vezes naturalizadas. Assim, faço uma reflexão sobre 0 ensino de enfermagem para entender como se produz este sujeito, a enfermeira. Proponho dar ao texto um título interrogativo para que, ao pensar sobre a educação, nos desloquemos e façamos um movimento contrário ao que geralmente fazemos, das respostas para as perguntas. Para me auxiliar nesta tarefa lembro um pensamento de Larrosa:

0 discurso pedagógico dominante, dividido entre a arrogância dos cientistas e a boa consciência dos moralistas, está nos parecendo impronunciável. As palavras comuns começam a nos parecer sem qualquer sabor ou a nos soarem irremediavelmente falsas e vazias. $E$, cada vez mais, temos a sensação de que temos de aprender de novo a pensar e escrever, ainda que para isso tenhamos de nos separar da segurança dos saberes, dos métodos e das linguagens que já possuímos (e que nos possuem) ${ }^{(1: 7)}$.

Tais palavras permitem pensar de outro modo a educação, o que implica construir uma determinada consciência pessoal e profissional que sirva de princípio para a prática, de critério para a crítica e transformação da prática e de base para a auto-identificação do professor e da professora (2).

As atividades docentes e as pesquisas com as quais me envolvi ao longo da minha trajetória profissional, ao mesmo tempo em que me posicionaram em lugares em que a educação em enfermagem estava se desenvolvendo, também me conduziram, freqüentemente, para fora dela, colocando-me em circuitos onde esta educação estava sob análise e questionamento. E esse poder de estar dentro e poder olhar de fora tem sido produtivo. Contudo, ao fazer esta afirmação não tenho a pretensão de ser objetiva, de escrever algo que se pretenda universal ou de sistematizar algum conhecimento a que tenha chegado. Nem mesmo pretendo fazer prescrições, ou dizer como se deve agir, mesmo sabendo que deste modo meu discurso pode soar inseguro ou impróprio. Por outro lado, não penso que o que escrevo seja desprovido de efeitos.

Tomo a educação em enfermagem como produtora de enfermeiras de certo tipo. Deste modo, presto atenção às práticas pedagógicas onde se estabelecem, se regulam e se modificam as relações deste sujeito consigo mesmo e nas quais se constitui a experiência de si. Não me preocupo com o que é a enfermeira, mas como se constitui este profissional, os discursos que a produzem, as condições de possibilidade do aparecimento desta profissão no Brasil, os repertórios de modos de experiência de si, os dispositivos para formação de seus membros. Para sustentar as idéias que apresento, me apoio em minha Tese de Doutorado ${ }^{(3)}$. Nela pesquisei sobre o corpo em uma de suas inúmeras vias, a da saúde, para compreender como um determinado grupo que compõe essa área, no caso a Enfermagem, inventou e incorporou maneiras de conhecer e controlar o corpo, objeto de seu trabalho, nos seus modos de ensinar e cuidar de pacientes hospitalizados. A idéia da tese nasceu do meu olhar de enfermeira, professora e pesquisadora, sobre os corpos hospitalizados. A partir desse olhar, organizei uma leitura dos discursos, que compõem um conjunto de conhecimentos que devem ser ensinados às enfermeiras, para entender como se constrói o olhar delas sobre esses corpos.

\section{RECORRENDO À TESE}

Para dar conta de responder à pergunta que me incitou a produzir este texto, gostaria de destacar quatro achados da minha Tese. 0 primeiro está relacionado à disciplina de Anatomia, onde encontrei um discurso científico sobre o corpo. $\mathrm{Se}$, antes dessa disciplina, o corpo morto servia apenas a rituais, agora, a partir da dissecação, institui-se o cadáver como algo que deve ser visto e explorado geograficamente, como figura exterior e objetiva. A disciplina de Anatomia produz determinados saberes e poderes sobre o corpo que marcam profundamente a formação na área da saúde, uma vez que até hoje nos mantemos fiéis à sua narrativa. 0 filósofo francês Michel Foucault considerou decisivo para a nossa cultura o fato de que o primeiro discurso científico por ela sustentado devesse ter passado por esse momento de morte, considerando que 0 homem ocidental só pode se constituir aos seus próprios olhos, como um objeto da ciência em referência a sua própria destruição ${ }^{(4)}$. Assim, destaco que ao posicionar o cadáver como o primeiro contato da estudante com um corpo humano, objeto de sua futura prática, se estabelecesse um determinado modo de subjetivação das enfermeiras.

Ao analisar as técnicas de enfermagem como o primeiro saber organizado e sistematizado da enfermagem, observei que se apresentam muito mais voltadas para a tarefa e para a arrumação e controle do ambiente, produzindo um esquadrinhamento do tempo e do espaço, onde o corpo é controlado e trabalhado detalhadamente nos seus gestos e atitudes. Tais técnicas se exercem sobre todo o trabalho da enfermeira e sobre a vida do paciente, do nascimento até a morte. Nada escapa da disciplina que controla qualquer ação, prevendo uma codificação instrumental do corpo. Destaco que a aprendizagem das técnicas nos laboratórios de enfermagem das escolas promove um segundo encontro da estudante, agora com um boneco, feito de material inerte, que simula o corpo que será cuidado. Com isso não estou criticando o uso desses bonecos e nem querendo dizer que as estudantes deveriam treinar nos corpos dos pacientes hospitalizados, mas apontar que o uso desses bonecos não é isento de efeitos e constitui peça importante na maquinaria que produz as enfermeiras.

Um terceiro achado foi relativo ao exame físico. Destaquei seu ritual e a visibilidade que produz no corpo do paciente internado, que é diferenciado e escrutinado a partir desse detalhado cerimonial. 0 exame é um ritual de objetivação que torna o sujeito um objeto e, além disso, subjetiva-o como um paciente, como portador de anormalidades, que por isso necessita ser normalizado, isto é, tratado. Por outro lado, esse ritual implica em distanciamento, pois aí se transmite um saber do profissional que está examinando, ao mesmo tempo em que 
se estabelece um campo de saber. 0 paciente aprende que 0 seu corpo pode informar, comunicar e esclarecer, desde que submetido a um escrutínio adequado. Dessa forma, o corpo é chamado a se expressar e ser traduzido em palavras, números ou imagens, se transformando em um texto que não carrega mais os traços que lhe dão sentido, sendo, então, possível pensar que, ao serem transformados em texto, são atribuídos outros sentidos e outros efeitos aos corpos ${ }^{(5)}$. Meu argumento é de que o olhar da enfermeira, produzido por esses textos, tem o poder de fazê-la pensar sobre o corpo a partir de categorias consideradas apenas para classificar, enquadrar e prescrever. Como se pertencer a um determinado quadro proporcionasse ao paciente uma identidade constituída e fixada.

Com estes comentários aponto o quarto achado da minha Tese que eu gostaria de comentar. Ao considerar os diagnósticos de enfermagem, tentei mostrar porque este conhecimento, tal como está organizado, poderia ser um dos dispositivos produtores de determinado modo de pensar sobre o corpo. Relembro que para elaborar os diagnósticos de enfermagem foi preciso que as enfermeiras produzissem uma extensa classificação que aceitasse todo o leque das possibilidades humanas. Destaco os diagnósticos de enfermagem como um espaçoso arquivo, que se organiza para conter todas as pastas, que por sua vez contenham todos os itens relativos à possibilidade de adoecer ou ser saudável. 0 fato de criar categorias não seria o maior problema, este seria o fato de, ao criar uma categoria, pretender que esta represente uma totalidade, que supostamente conduziria a uma maior objetividade e poderia abrigar todos os pacientes, como se todos fossem iguais. Quando algum deles não se enquadrar na categoria, produz-se outra, e mais outras, até que todos sejam enquadrados, se é que isso é possível. Assim, os diagnósticos de enfermagem compõem um aparelho documental que possibilita o crescimento do poder, pois permitem que as enfermeiras, ao produzirem uma rede objetiva de codificação, produzam um discurso que tem determinadas regras de construção, determinados conceitos e uma analogia estrutural e formal com o discurso científico, que quer introduzir outras formas de saber além dessas que hoje circulam, que tem ambição de usufruir do poder reservado àqueles que formulam um discurso científico. Entendo que essas tecnologias operam para produzir certo jeito de olhar para o corpo, que vai conformando o olhar da enfermeira para que ela transforme indivíduos em pacientes, anulando suas diferenças de sexo, gênero, geração ou raça/etnia, como se todos fossem iguais e não tivessem história ou identidade.

Deste modo, aponto tais estratégias de ensino como representativas de um determinado modo de ensinar enfermagem que tem sido produtivo e, por isso, tem se conservado ao longo da formação das enfermeiras no Brasil. Penso que olhar para os corpos considerando saberes provenientes de cadáveres, treinar em bonecos de material inerte, examinar e classificar corpos tem efeitos que me parecem que estão longe do que consideramos humanizador, holístico ou que respeitem a individualidade do ser humano.
Mais ainda, acho que é impossível pensar sobre o ensino de enfermagem sem considerar esses discursos e essas práticas, pois é aí, na articulação complexa desses discursos e práticas, que enfermeiras e enfermeiros se constituem no que são, pois entendo que a educação, além de construir e transmitir uma experiência vista como "objetiva" do mundo, constrói e transmite também a experiência que as pessoas têm de si e dos outros como "sujeitos", isto é, tanto o que é ser pessoa como o que para cada um é ser ele mesmo ${ }^{(2)}$.

\section{SOBRE AS CONDIÇÕES DE POSSIBILIDADE}

Um outro aspecto que me instiga a pensar de outro modo sobre o ensino de enfermagem, é relativo às condições de possibilidade do surgimento da Enfermagem Moderna no Brasil. Ao resgatar fragmentos da história da Enfermagem, podemos reconstituir a organização de seu regime de práticas e constatar que, ao longo destes anos, se desenvolveu uma história pontuada pela disciplina, pela ordem, por uma cultura de si dentro de instituições como a escola, o hospital e, mesmo, o exército. Relembro aqui momentos da história da Enfermagem pontuados pela presença da enfermeira na guerra, com 0 objetivo de preservar o corpo do soldado, através de duas personagens - Florence Nightingale e Ana Néri - que são exaustivamente reverenciadas em nossa profissão.

Penso que, se quero entender a proveniência dos saberes que determinam certa visão sobre o corpo do outro, se quero conhecer os efeitos que são produzidos por determinada maneira de ensinar e aprender sobre este corpo, preciso reconstituir os processos geradores, não para atribuir-lhes um valor em si, uma positividade, um progresso. Pois, como um sinal de reconhecimento a Foucault, não tomarei o ponto em que nos encontramos como o final de um progresso que nos caberia reconstituir com precisão na história. Foucault considerava um mau método esta forma de problematização. Ao invés disso, preocupava-se em perguntar: como isso se passa? Pois o que se passa agora não é nem melhor, nem mais importante e nem melhor explicado do que o que se passou antes. Com Foucault, fica evidente que o importante não é buscar as transformações que certo objeto sofreu ao longo do tempo em uma determinada cultura, mas tornar problemático e, portanto, histórico, tudo o que é visto como "objeto natural" a priori. Assim, há de se perseguirem as condições de possibilidade que provocam o surgimento de determinadas práticas ${ }^{(6)}$.

Observo a Enfermagem como uma profissão que surge no Brasil atrelada às políticas públicas, num momento em que 0 saber médico se institucionaliza e começa a se organizar no hospital. Portanto associada ao Estado, ao saber médico e ao hospital. Mesmo tendo sido organizada para atender às necessidades da saúde pública, de acordo com as versões históricas que hoje circulam, foi profundamente influenciada pelo modelo anglo-americano, caracterizado pelo estudo sistemático das doenças e o conseqüente cuidado ao doente, e, portanto, centrada no ambiente hospitalar. Tal afirmação está apoiada em artigo ${ }^{(7)}$, publicado na Revista Brasileira de Enfermagem em 1937, onde Zaira Cintra Vidal cita que a 
educação da enfermeira está subordinada a dois fatores: à instrução recebida na sala de aula e à experiência nos diferentes serviços do hospital. No texto, a autora explica a estratégia que era usual na época: na sala de aula a enfermeira se preparava teoricamente para cuidar do doente e, no hospital, ela adquiria a habilidade prática necessária à profissão. Reforça, ainda, que a enfermaria era o traço de união entre o ensino teórico e o prático de uma escola, e que era muito importante a aluna aplicar seus conhecimentos na enfermaria. Assim, observo que o "treinamento" do olhar da enfermeira era focado no corpo do paciente hospitalizado, isto é, doente. Depois, estes saberes e fazeres eram, então, "adaptados" aos corpos sadios que seriam objeto do trabalho das enfermeiras de saúde pública, tendo como cenário as unidades sanitárias ou os domicílios. Portanto, havia uma ênfase nas atividades práticas nos hospitais. Esta é também a trajetória da Enfermagem, tanto nos Estados Unidos como na Inglaterra, onde as escolas fundadas no final do século XIX eram vinculadas aos hospitais particulares, permitindo a formação de mão de obra em menos tempo e com menor custo. No modelo inglês, a Enfermagem se organiza durante a guerra como uma necessidade de melhorar a assistência ao soldado ferido, portanto também no hospital. Assim, a enfermagem profissional nasce no hospital, uma das instituições reconhecidas como instituições de seqüestro e que, ao lado de outras, teria produzido o que hoje se considera o "homem moderno", já que ali se desenvolve um grande investimento sobre o corpo através da disciplina(4).

Para ilustrar o que digo, invoco Valesca Paixão, que destaca que um dos fatores que mais contribuiu para a vitória do sistema proposto por Florence Nightingale foi a rigorosa seleção das candidatas, já que ela só permitia o "ingresso de jovens educadas e de elevada posição social” (8:49). Resgato essa informação para mostrar que as enfermeiras americanas, ao implantarem a Enfermagem Moderna no Brasil, nada mais fizeram do que transpor para cá os princípios organizadores de Florence Nightingale e da Enfermagem inglesa. Para garantir que as jovens se mantivessem educadas e que, portanto, fossem preservadas estas condições, as escolas foram dotadas de internatos que garantiam a "elevação moral necessária ao exercício profissional”, além de, eu acrescentaria, constituírem mais um poderoso espaço de disciplinamento, através de regras e controles que eram exercidos pelos responsáveis pela escola. Para cumprir esta meta, as escolas de Enfermagem no Brasil mantiveram internatos em suas sedes até a década de 1960. Os mesmos cumpriram um papel regulador da conduta das enfermeiras e, hoje, são objeto de inúmeros estudos, pois são vistos como um dos "pilares do projeto de construção da profissão" em nosso país. Podemos pensar que, nestes lugares, estariam sendo fabricadas as "almas das enfermeiras"( 9 .

A enfermagem surge como um trabalho subordinado ao do médico, uma vez que a inspeção dos corpos dos pacientes, que antes era descontínua e rápida, se transforma em meados do século XVIII quando, ao iniciar sua atuação no ambiente hospitalar, o médico coloca o doente em situação de exame permanente. Era, então, necessário que um outro elemento, no caso a enfermeira, executasse o papel determinado, mas subordinado ao do médico, na técnica de exame, pois o médico não podia e não queria permanecer todo o tempo no hospital ${ }^{(10)}$. Posteriormente, quando Florence Nightingale organiza a Enfermagem como profissão, ela permanece subordinada ao trabalho do médico. E nem poderia ser diferente, consideradas as condições dos hospitais naquela época, onde a figura do médico já estava introjetada na instituição, aí ocupando um espaço privilegiado. Em minha pesquisa, ao analisar exemplares da Revista Brasileira de Enfermagem, observei que até a década de 1950 os textos fazem recorrentemente referência ao saber do médico, inclusive nas técnicas de enfermagem, que, ao serem apresentadas, trazem a informação de que teriam sido revisadas ou autorizadas por determinado médico que geralmente era professor de Faculdades de Medicina. Portanto, enquanto foi preciso, a Enfermagem se aproximou da categoria médica, pois o fato de estar vinculada ao trabalho médico permitiu que a enfermeira usufruísse seu prestígio, já que, naquela época, havia no hospital cuidadores que não tinham reconhecimento profissional. Florence Nightingale, preocupada em organizar uma profissão, vinculou-a a um saber que tinha status, um saber próximo da ciência.

Posteriormente, o desenvolvimento profissional da Enfermagem, representado principalmente pelo ingresso na Universidade e pela preocupação em construir um saber próprio, faz circular um outro discurso sobre a profissão: a Enfermagem como profissão autônoma e participante, em igualdade de condições, com os demais profissionais da saúde. Nos textos da revista isto é bem evidente, pois não se encontra autor médico e nem mais referência ao seu saber para legitimar o conhecimento.

\section{SOBRE A ENFERMAGEM COMO PROFISSÃO}

Como terceiro ponto, destaco que a Enfermagem como profissão se instala no Brasil atrelada às políticas públicas, as quais seguia sem muitos questionamentos, e, naquele momento, apesar dos discursos em contrário, essas políticas privilegiavam a assistência hospitalar. Este caráter colaborativo e um tanto acrítico esteve presente também nos Estatutos da ABEn, ali permanecendo até os anos de 1960, e definia que a Associação tinha como uma das suas finalidades a colaboração na execução dos programas de governo, eu acrescentaria, fossem eles quais fossem, o que fica evidente ainda hoje na excessiva dependência que a ABEn tem tido das verbas públicas.

Por outro lado, observo que esta preocupação permanece, evidenciando a obediência e disciplinamento, quando observamos a preocupação em seguir as políticas educacionais, como se nelas existissem verdades que as tornam intrinsecamente boas. Trago como exemplo a preocupação que os cursos têm de implantar as Diretrizes Curriculares Nacionais (DCN's) e seus pressupostos ${ }^{(11)}$. Quem já não ouviu, à exaustão, referências a levar os alunos dos cursos de graduação em saúde a aprender a aprender, que engloba aprender a ser, aprender a fazer, aprender a viver juntos e aprender a conhecer... Ou Enfermeiro, com formação generalista, humanista, crítica e reflexiva...Ou ainda permitir que os currículos propostos possam construir perfil acadêmico e profissional com competências, habilidades e conteúdos, dentro de perspectivas e abordagens 


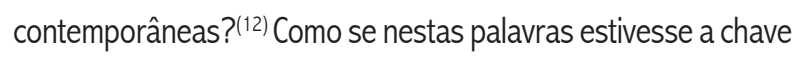
da boa formação e, ao implantá-las, esta estaria assegurada. Em relação a este caráter crítico e reflexivo que o ensino teria, poderia se perguntar: será que estes professores que querem formar alunos críticos e reflexivos fazem uma reflexão e, portanto, uma crítica sobre as diretrizes propostas? É interessante destacar que nas lutas pela definição legal destas DCN, interesses conflitantes se manifestaram e aquilo que hoje é visto como conquista é produto de uma batalha intensa e pertinaz que se dá no plano da linguagem no sentido de assegurar a inclusão de idéias, significados e definições compartilhadas, onde alguns acordos são estabelecidos e outros tantos são silenciados ou têm sentidos ambíguos, permanecendo algumas áreas de disputa, onde grupos de diferentes posições de poder disputam espaços possíveis que garantam a imposição de suas idéias e opiniões ${ }^{(13)}$.

\section{PARA CONCLUIR}

Por que é importante destacar este paradoxal início brasileiro? Qual a sua relevância para a pergunta que orienta

\section{Referências}

1 Larrosa J. Pedagogia profana: danças, piruetas e mascaradas. Porto Alegre (RS): Contrabando; 1998.

2 Larrosa J. Tecnologias de eu e educação. In: Silva TT, organizador. 0 sujeito da educação: estudos foucaultianos. Petrópolis (RJ): Vozes; 1994.

3 Kruse MHL. Os poderes dos corpos frios: das coisas que se ensinam às enfermeiras. Brasília (DF): ABEn; 2004.

4 Foucault M. 0 nascimento da clínica. Tradução de Roberto Machado. Rio de Janeiro(RJ): Forense Universitária; 1998.

5 Vargas MO. Corpus ex machina: a ciborguização da enfermeira no contexto da terapia intensiva [disser tação de mestrado]. Porto Alegre (RS): Faculdade de Educação/ UFRGS; 2002.

6 Sant'anna D. 0 corpo entre antigas referências e novos desafios. Cad Subjet 1998 dez; 7(2): 275-84.

7 Vidal ZC. 0 trabalho prático nas enfermarias. An Enferm 1937 maio; 5(9): 39-41. este texto? Entendo que esta origem no ambiente hospitalar, motivada pelas políticas públicas e dependente da autoridade do médico, produz poderosas marcas no saber e fazer da enfermagem e conseqüentemente naquilo que aprendemos e ensinamos. Não se trata de fazer uma história das coerções disciplinares, mas de mostrar que os mecanismos disciplinares que permeiam o modo como ensinamos podem nos impedir de pensar de outro modo o ensino de enfermagem, evitando ou dificultando outras formas de ver o poder, de conferir status ao saber e de produzir subjetividades.

Com estas reflexões que propõem que repensemos a educação em enfermagem, eu concluo dizendo que ao organizar este texto tentei fugir de uma narrativa que compusesse um conjunto, pois creio que, para além de saberes disciplinados, de métodos ou de recomendações úteis, ou mesmo de respostas seguras, talvez seja a hora de tentar trabalhar neste campo em que nos encontramos de uma forma que se pretende indisciplinada, insegura e imprópria, já que situada à margem da impessoalidade das metodologias dominantes que, mesmo sem vontade de prescrever como se deve agir, não abandonam a idéia de modificar e iluminar as práticas ${ }^{(2)}$.

8 Paixão W. A formação moral da estudante de enfermagem. Rev Bras Enferm 1952 jan; 5(1): 17-23.

9 Varela J, Alvarez-Uría F. Prólogo. In: Foucault M. Saber y verdad. Madrid (ES): La Piqueta; 1991.

10 Foucault M. Vigiar e punir. Tradução de Raquel Ramalhete. $20^{\mathrm{a}} \mathrm{ed}$. Petrópolis (RJ): Vozes; 1999.

11 Meyer DE, Kruse MHL. Acerca de diretrizes curriculares e projetos pedagógicos: um início de reflexão. Rev Bras Enferm 2003 jul/ago; 56(4): 335-39.

12 Ministério da Educação (BR). Resolução CNE/CES n 3, de 7 de novembro de 2001. Diretrizes curriculares nacionais para os cursos de enfermagem. Brasília (DF); 2001.

13 Bujes MIE. Infância e maquinarias. Rio de Janeiro (RJ): DP\&A; 2002.

\section{Nota}

aPalestra proferida por ocasião da aula inaugural da EEAN, em 8 de março de 2006. 